gentamicin. She was discharged at the age of 54 days when her weight was $2.35 \mathrm{~kg}$. She failed to attend an outpatient appointment and died unexpectedly at the age of 106 days. The coroner's post mortem examination showed no definite cause of death, the only positive findings being many petechiae on the surface of the thymus, heart, and lungs.

\section{Discussion}

The infant's mother had a toxic blood concentration of paracetamol and she was fortunate to escape liver damage. The giving of methionine may have contributed to this favourable outcome. Methionine was not used in the infant as more than 12 hours had elapsed since the mother's ingestion of paracetamol and we knew of no reports of the use of this potentially toxic drug in the neonatal period.

Paracetamol is less toxic in the newborn mouse than in the adult because adequate glutathione stores are present before the ability to produce the toxic metabolite develops. ${ }^{5}$ It is unclear, however, whether the same conditions prevail in the human neonate. In this case the infant was exposed to potentially toxic blood values of paracetamol but suffered no liver damage and it seemed important to establish the contribution of exchange transfusions to this outcome.

Plasma paracetamol concentrations did not decrease continuously in the infant but showed a rebound effect after each of the first 3 exchange transfusions. This was probably because paracetamol sequestered in the tissues was released after each exchange before being subsequently removed from the circulation. Despite exchange transfusion, the plasma half life of paracetamol (26 hours) was considerably prolonged.

The plasma values of paracetamol and its metabolites are shown in Fig. 1. These were separated and measured by reverse phase high performance liquid chromatography using $0 \cdot 1 \mathrm{M}$ potassium dihydrogen phosphate $/ 0.1 \%$ formic acid $/ 0.45 \%$ isopropanol as elution solvent and $\mathrm{N}$-acetyl-3 aminophenol as internal standard. The finding of a fall in glucuronide conjugates similar to that of the parent drug suggests that this mainly reflects maternal metabolism. The rise in sulphate conjugates, however, shows that this infant of 29 weeks' gestation was able to conjugate paracetamol by sulphatation. Cysteine and mercapturate conjugates were found to increase as well, thus supporting the in vitro findings that the mixed function oxidase system is active in the preterm infant and glutathione is available to conjugate with the metabolites produced. ${ }^{3}$ If exchange transfusions had not been performed glutathione stores might have been depleted leading to hepatic necrosis.

Dr Fysh is supported by the National Medical Research Fund.

\section{References \\ 1 Miller RP, Roberts RJ, Fischer LJ. Acetaminophen elimination kinetics in neonates, children, and adults. Clin Pharm Ther 1976; 19: 284-94. \\ ${ }^{2}$ Levy G, Khanna NN, Soda DM, Tsuzuki O, Stern L. Pharmacokinetics of acetaminophen in the human neonate: formation of acetominophen glucuronide and sulphate in relation to plasma bilirubin concentration and D-glucaric acid excretion. Pediatrics 1975; 55: 818-25. \\ 3 Rollins DE, Von Bahr C, Glaumann $H$, Moldeus $P$, Rane A. Acetaminophen: potentially toxic metabolite formed by human fetal and adult liver microsomes and isolated fetal liver cells. Science 1979; 205: 1414-6. \\ 4 Prescott LF, Wright N, Roscoe P, Brown SS. Plasma- paracetamol half-life and hepatic necrosis in patients with paracetamol overdosage. Lancet 1971; i: 519-22. \\ 5 Hart JG, Timbrell JA. The effect of age on paracetamol hepatotoxicity in mice. Biochem Pharmacol 1979; 28: 3015-7.}

Correspondence to Dr S Lederman, Department of Child Health, King's College Hospital, Denmark Hill, London SE5 8RX.

Received 11 March 1983

\title{
Central venous catheters for out-patient management of malignant disorders
}

\author{
M STOCKWELL, M ADAMS, M ANDREW, G CAMERON, AND K PAI \\ The Departments of Pediatrics and Surgery, McMaster University Health Sciences Centre, \\ Hamilton, Ontario, Canada
}

SUMMARY The use of tunnelled central venous catheters in children with malignant disorders is an effective and safe way of giving out-patient chemotherapy and supportive care. The benefits include ready venous access, ease of administration of chemotherapy, decreased time spent in the outpatient clinic, and less anticipatory vomiting and emotional trauma for patients, parents, and staff.
Children requiring intensive intravenous chemotherapy for the management of malignant disorders undergo physical and psychological trauma because of repeated venepuncture. Prolonged and repeated use of peripheral veins may also result in local pain from thrombosis or drug extravasation. Indwelling right atrial catheters have been used for giving total parenteral nutrition ${ }^{12}$ and for facilitating bone marrow transplantation, ${ }^{3}$ in-patient treatment 
of children with malignant diseases, ${ }^{4}$ and treatment of acute leukaemia in adults. ${ }^{5}$ We describe the use of catheters in the long term out-patient management of children with malignant disorders.

\section{Patients and methods}

Our study spanned a period of 21 months (August 1980 to May 1982) and we recorded information on age, diagnosis, criteria for placement, catheter size, utilisation, duration of use, and complications. The procedure for catheter placement is described in published reports ${ }^{26}$ and the Figure shows the anatomical relations. In our experience a general anaesthetic was preferable to a local anaesthetic for children. Subsequent care of the catheter consisted of flushing it every 10-14 hours with $6 \mathrm{ml}$ of heparin/saline solution $(0.3 \mathrm{ml}$ of $1: 1000$ heparin in $30 \mathrm{ml}$ normal saline) and weekly cleansing and redressing of the exit site and cap changes. Patients and families were taught to care for the catheters at home with initial assistance from a visiting nurse.

\section{Results}

Over the period of the study 24 patients aged from 4 months to 19 years had catheters (Hickman (14) and Broviac (10). Thirteen children had leukaemianon-lymphoblastic leukaemia (4), relapsed acute lymphoblastic leukaemia (8), and high risk acute lymphoblastic leukaemia (1) -2 children had lymphoma, 8 had solid tumours, and 1 had Evans's syndrome.

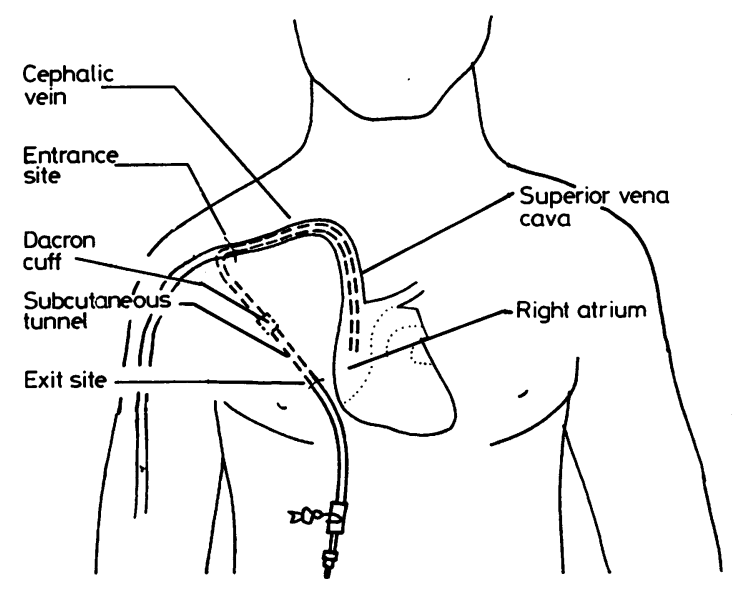

Figure Diagram of the anatomical relations in the placement of a tunnelled central venous catheter.
Indications for a catheter were: intensive chemotherapy, poor peripheral venous access, emotional trauma of frequent venepunctures, and facilitation of terminal care. All but 3 catheters were placed under general anaesthesia. The catheters were used for blood sampling (24), administration of chemotherapy (24) and other medications (24), blood products (22), intravenous fluids (20), and total parenteral nutrition (5). One patient received 11 agents per 24 hours for 7 consecutive days. At the time of this report catheters had been in place from 10 to 330 days (median, 114 days), 15 catheters were functional, 3 had been removed electively after completion of treatment, and 6 patients had died of their primary disorder with a functional catheter in place.

\section{Complications}

Complications are listed in the Table. All children had at least 1 febrile episode with the catheter in place. There were 49 episodes of neutropenia for a total of 683 days. Febrile, neutropenic patients were treated with broad spectrum antibiotics and in all but 1 the infection resolved. In this patient the organism cultured was resistant to all the antibiotics used. The other 4 children with positive blood cultures (Staphylococcus aureus (3), Escherichia coli (1)) were treated until the fever resolved, the absolute neutrophil count rose to greater than $1.0 \times 10^{9} / 1$, and repeat cultures were negative. This took approximately 10 days.

\section{Discussion}

The tunnelled right atrial catheter provides long term safe venous access in children being treated for

Table Complications during use of right atrial catheters in children with malignant disorders $(n=24)$

\begin{tabular}{|c|c|c|}
\hline Complications & No & Treatment \\
\hline Thrombosis of innominate vein & 1 & Catheter replacement \\
\hline Postoperative swelling & 2 & Resolved without intervention \\
\hline Disconnection from IV infusion & 2 & $\begin{array}{l}\text { Luer lock stop cock and } \\
\text { additional taping }\end{array}$ \\
\hline Removal of clamp and cap & 1 & $\begin{array}{l}\text { Replacement with a new } \\
\text { clamp and cap, } T \text {-shirt } \\
\text { worn at all times }\end{array}$ \\
\hline Temporary blockage & 6 & $\begin{array}{l}\text { Clearance with } \\
\text { heparin/saline* }\end{array}$ \\
\hline Leaks and tears & 3 & Repair \\
\hline Cuff movement & 3 & Extra taping at exit site \\
\hline Exit site wound infection & 5 & Topical and oral antibiotics \\
\hline Positive blood cultures & 5 & $\begin{array}{l}\text { Oral and intravenous } \\
\text { antibiotics }\end{array}$ \\
\hline
\end{tabular}

* Use extra saline and clear after administration of blood products. 
malignant disorders. Our experience shows that although there were minor problems in using the catheter in children, there were no complications resulting in major morbidity. In no patient was a catheter removed because of sepsis and this problem has been reported to be only $3 \%$ in larger groups of older patients. ${ }^{6}$

The reasons for our success in using catheters are the motivation and thorough training of the families and the precautions we have introduced to reduce the risks attending the use of catheters in young children. Education of our families consists of a video tape on catheter care, practical teaching sessions in the clinic, and a visiting nurse until the families can manage independently. The length of training time varies from 1 week to 1 month. Catheters are kept dressed at all times with either Op-site Spray Dressing or gauze, and for further security the catheter is taped to the chest wall. Smaller children wear vests or T-shirts to discourage them from playing with the catheter. Luer lock stop cocks are used for intravenous treatment to avoid accidental disconnection, and trained staff only have access to the catheter during hospital admissions and clinic visits.

We observed several benefits from the use of these catheters in children with malignant disordersreadily available venous access; easy administration of intravenous chemotherapy without risk of extravasation; decreased time spent in clinic; less emotional trauma for patients, parents, and staff; and less anticipatory vomiting. The latter benefit was observed in 4 children who were refractory to antiemetics and behaviour modification and whose anticipatory vomiting resolved immediately when venepunctures were no longer necessary.

In our experience the long term use of tunnelled central venous catheters in children with malignant disorders is associated with acceptable morbidity and results in many benefits in the provision of specific and supportive care.

We thank Dr R Barr.

\section{References}

1 Filler RM, Eraklis AJ. Care of the critically ill child: intravenous alimentation. Pediatrics 1970; 46: 456-61.

2 Broviac JW, Cole JJ, Scribner BH. A silicone rubber atrial catheter for prolonged parenteral alimentation. Surg Gynecol Obstet 1973; 136: 602-6.

3 Hickman RO, Buckner CD, Clift RA, Sanders JE, Stewart P, Thomas ED. A modified right atrial catheter for access to the venous system in marrow transplant recipients. Surg Gynecol Obstet 1979; 148: 871-5.

4 Thomas M. The use of the Hickman catheter in the management of patients with leukaemia and other malignancies. Br J Surg 1979; 66: 673-4.

5 Blacklock HA, Hill RS, Clarke AG, Pillai MV, Matthews JRD, Wade JF. Use of modified subcutaneous right atrial catheter for venous access in leukaemic patients. Lancet 1980; i: 993-4.

6 Bjeletich J, Hickman RO. The Hickman indwelling catheter. Am J Nurs $1980 ; 80$ : 62-5.

Correspondence to Dr M Andrew, Department of Paediatrics, Room HSC-3N 26E, McMaster University Health Sciences Centre, 1200 Main Street West, Hamilton, Ontario L85 4N3.

Received 16 May 1983

\title{
T cell lymphocytosis with neutropenia
}

\author{
J A MURRAY AND J S LILLEYMAN
}

Department of Haematology, The Children's Hospital, Sheffield

SUMMARY A gross $\mathbf{T}$ cell lymphocytosis developed in an otherwise healthy 5 year old girl and has persisted for nearly 3 years. It is associated with neutropenia and seems to be typical of a rare adult disorder that may be a type of $T$ cell chronic lymphocytic leukaemia.

'T cell lymphocytosis with neutropenia' is the cautious name given to a rare syndrome that occurs in adults and there is doubt whether it is a clonal neoplasm or merely a reactive pleocytosis. ${ }^{1}$ It has never been described in a child, and we report its occurrence in a young girl.

\section{Case report}

A 4 year old girl presented in 1979 with a moderate normochronic anaemia. Her father and 5 other family members had had splenectomy performed for hereditary spherocytosis and the same diagnosis was confirmed in this child. Splenectomy was 